Article

\title{
Neohesperidin Dihydrochalcone and Neohesperidin Dihydrochalcone-O-Glycoside Attenuate Subcutaneous Fat and Lipid Accumulation by Regulating PI3K/AKT/mTOR Pathway In Vivo and In Vitro
}

\author{
Minseo Kwon ${ }^{1,+}$, Yerin Kim ${ }^{1,+}{ }^{,}$Jihye Lee ${ }^{1}{ }^{1}$, John A. Manthey ${ }^{2}$, Yang Kim ${ }^{3}$ and Yuri Kim ${ }^{1, *}$ \\ 1 Department of Nutritional Science and Food Management, Ewha Womans University, Seoul 03760, Korea; \\ minseu94@naver.com (M.K.); elle_rossy@naver.com (Y.K.); boboom38@naver.com (J.L.) \\ 2 U.S. Horticultural Research Lab, U.S. Department of Agriculture, Agricultural Research Service, \\ 2001 South Rock Road, Fort Pierce, FL 34945, USA; john.manthey@usda.gov \\ 3 Center for Food \& Bioconvergence, Seoul National University, Seoul 08826, Korea; yankim@snu.ac.kr \\ * Correspondence: yuri.kim@ewha.ac.kr; Tel.: +82-2-3277-4485; Fax: +82-2-3277-2862 \\ + These authors contributed equally to this work.
}

check for

updates

Citation: Kwon, M.; Kim, Y.; Lee, J.; Manthey, J.A.; Kim, Y.; Kim, Y.

Neohesperidin Dihydrochalcone and Neohesperidin Dihydrochalcone-OGlycoside Attenuate Subcutaneous Fat and Lipid Accumulation by Regulating PI3K/AKT/mTOR Pathway In Vivo and In Vitro. Nutrients 2022, 14, 1087. https:// doi.org/10.3390/nu14051087

Academic Editor: Susanne Klaus

Received: 14 December 2021 Accepted: 23 February 2022 Published: 4 March 2022

Publisher's Note: MDPI stays neutral with regard to jurisdictional claims in published maps and institutional affiliations.

Copyright: (C) 2022 by the authors. Licensee MDPI, Basel, Switzerland. This article is an open access article distributed under the terms and conditions of the Creative Commons Attribution (CC BY) license (https:// creativecommons.org/licenses/by/ $4.0 /)$.

\begin{abstract}
Neohesperidin dihydrochalcone (NHDC), a semi-natural compound from bitter orange, is an intense sweetener. The anti-obesity effects of NHDC and its glycosidic compound, NHDC-Oglycoside (GNHDC), were investigated. C57BLKS/ J db/db mice were supplemented with NHDC or GNHDC (100 mg/kg b.w.) for 4 weeks. Body weight gain, subcutaneous tissues, and total adipose tissues (sum of perirenal, visceral, epididymal, and subcutaneous adipose tissue) were decreased in the NHDC and GNHDC groups. Fatty acid uptake, lipogenesis, and adipogenesis-related genes were decreased, whereas $\beta$-oxidation and fat browning-related genes were up-regulated in the sweetener groups. Furthermore, both sweeteners suppressed the level of triacylglycerol accumulation, lipogenesis, adipogenesis, and proinflammatory cytokines in the 3T3-L1 cells. The PI3K/AKT/mTOR pathway was also down-regulated, and AMP-acttvated protein kinase (AMPK) was phosphorylated in the treatment groups. These results suggest that NHDC and GNHDC inhibited subcutaneous fat and lipid accumulation by regulating the PI3K/AKT/mTOR pathway and AMPK-related lipogenesis and fat browning.
\end{abstract}

Keywords: neohesperidin dihydrochalcone; glycoside; obesity; subcutaneous adipose tissue; lipogenesis; $\mathrm{PI} 3 \mathrm{~K} / \mathrm{AKT} / \mathrm{mTOR}$

\section{Introduction}

Obesity is defined as excessive fat accumulation that causes serious health problems. The World Health Organization (WHO) has reported that obesity increased around threefold worldwide from 1975 to 2016 [1].

For these reasons, WHO proposed obesity as a global epidemic in the 21st century at the WHO Consultation on Obesity [2]. Being obese is also associated with diabetes mellitus [3,4], cardiovascular diseases [5,6], and cancers [4], all associated with metabolic disorders. There are several fat accumulation-related mechanisms, including lipogenesis or adipogenesis [7]. On the contrary, $\beta$-oxidation [8] and fat browning $[9,10]$ are inhibitory mechanisms of fat accumulation.

Sugar consumption has dramatically increased since the mid-1960s [11,12], and sugarsweetened beverages are considered to be the main driving factor [13]. The WHO has strongly recommended reducing sugar intake levels to less than $10 \%$ of the total energy intake [14]. Previous studies have shown that increased sugar consumption could enhance the prevalence of obesity in children and adults $[15,16]$. 
Alternative sweeteners have been suggested as a solution, in order to reduce sugar consumption. Sweeteners are classified into bulk sweeteners and intense sweeteners [17]. They are divided into these two categories depending on their calorie content. Bulk sweeteners produce calories, whereas intense sweeteners generate no or only minimal caloric value. Intense sweeteners also possess higher relative sweetness than sucrose [18]. Thus, their use is expected to prevent obesity or type 2 diabetes mellitus by using alternative sweeteners as a substitute for sugar.

Neohesperidin dihydrochalcone (NHDC) is an intense sweetener. It is extracted and processed from neohesperidin, its parent flavanone [19]. Flavanone glycosides are mainly found in the peels of oranges, and the dihydrochalcone form is synthesized through hydrogenation [20]. NHDC is a semi-natural compound manufactured from neohesperidin, a naturally occurring flavonoid obtained from bitter orange, Citrus aurantium [19,21], and it possesses high solubility and stability. The relative sweetness of NHDC is 250-2000 times higher than a sucrose solution [22,23]. In addition, NHDC can be utilized for masking the bitterness of other compounds [24]. It has been reported that this functional alternative sweetener also exerts antioxidant or anti-inflammatory effects $[25,26]$.

Glycoside is a compound with one or more sugars linked by a glycosidic bond to non-sugar molecules [27]. There are four types of glycoside according to the location of the linkage: $\mathrm{O}-, \mathrm{C}-, \mathrm{N}-$, and S-glycoside. Glycosides are known to exert anti-obesity [28] or anti-diabetic effects [29]. Some glycosidic compounds prevent diabetes by targeting the sodium-dependent glucose cotransporter (SGLT), dipeptidyl peptidase IV (DPP-IV), glucagon-like peptide 1 (GLP1), and peroxisome proliferator-activated receptor gamma $(\mathrm{PPAR} \gamma)$ [30]. Previous studies reported that NHDC had a radical scavenging activity and inhibited the reactive oxygen species (ROS) [31] as well as exerted anti-inflammatory effects in a paraquat-induced acute liver injury model [26]. Although the anti-obesity effect of NHDC was studied in vitro [25], the effect of NHDC and its glycosides on adipose tissues and their mechanisms remain to be identified. Thus, in the present study, the decreased subcutaneous adipose tissue effects of both NHDC, its glycoside compound, GNHDC, as well as their molecular mechanisms were investigated both in vivo and in vitro.

\section{Materials and Methods}

\subsection{Materials}

NHDC (1-(4-((2-O-[6-Deoxy- $\alpha$-L-mannopyranosyl]- $\beta$-D-glucopyranosyl)oxy)-2,6dihydroxyphenyl)-3-[3-hydroxy-4-methoxyphenyl]-1-propanone), and NHDC-O-glycoside (1-(4-((2-O-[6-Deoxy- $\alpha$-L-mannopyranosyl]-(4-O- $\alpha$-D-glucopyranosyl]- $\beta$-D-glucopyranosyl) oxy)-2,6-dihydroxyphenyl)-3-[3-hydroxy-4-methoxyphenyl]-1-propanone) (GNHDC) were kindly provided by Dr. Manthey from the U.S. Horticultural Research Laboratory, Agricultural Research Service, U.S. Department of Agriculture (Figure 1). These chemicals were diluted to 30, 50, and $100 \mu \mathrm{M}$ NHDC in $0.2 \%$ dimethyl sulfoxide (DMSO) (Sigma-Aldrich, St. Louis, MO, USA) or GNHDC in $0.1 \%$ ethanol (Merck, Darmstadt, Germany) in a culture medium for the in vitro study. Both chemicals were dissolved in phosphate-buffered saline (PBS) for the in vivo study.

\subsection{Animal Studies}

Five-week-old male C57BLKS/J db/db mice were purchased from the Central Lab Animal Inc. (Seoul, Korea). A leptin receptor-deficient ( $\mathrm{db} / \mathrm{db}$ ) mice model was chosen to assess the effects of blood glucose levels in the present study. Therefore, C57BLKS/J db/db mice were selected to be the experimental animal model since this model has often been used for type 2 diabetes mellitus or metabolic disorder-related studies [32,33]. All mice were maintained individually at $22 \pm 2{ }^{\circ} \mathrm{C}, 50 \pm 5 \%$ humidity, and $12 \mathrm{~h} / 12 \mathrm{~h}$ light/dark cycles. The animals were randomly divided into three groups ( $n=9$ mice per group) based on both body weight and fasting blood glucose levels after an acclimation period of 2 weeks, as follows: animals fed PBS (Ctrl), animals fed $100 \mathrm{mg} / \mathrm{kg}$ body weight (b.w.) NHDC (NHDC), and animals fed $100 \mathrm{mg} / \mathrm{kg}$ b.w. GNHDC (GNHDC). All reagents were given as an oral 
gavage 5 days per week, for 4 weeks. They were fed a modified American Institute of Nutrition (AIN)-93G diet (Raonbio, Yongin, Korea) and water ad libitum. The composition of the AIN-93G diet is presented in Table 1. During the experimental period, body weight, food intake, and water intake were recorded twice a week. Fasting blood glucose levels were measured from the tail vein by using Accu-Check (Roche, Mannheim, Germany). The mice were fasted $12 \mathrm{~h}$ before euthanasia and anesthetized through isoflurane inhalation for 1-2 min [34]. After the mice were sacrificed, all the blood was centrifuged at $13,000 \times g$, at $4{ }^{\circ} \mathrm{C}$, for $15 \mathrm{~min}$. For adipose tissue dissection, we followed the protocol by Bagchi and MacDougald, 2019 [35]. For subcutaneous fat isolation, anterior subcutaneous adipose tissues located between the scapulae and posterior subcutaneous adipose tissues comprised of the dorsolumbar, inguinal, and gluteal parts were isolated [35]. Perirenal, visceral, and epididymal adipose tissues were also collected. Adipose tissues were rinsed with PBS and then frozen in liquid nitrogen. All samples were stored at $-80{ }^{\circ} \mathrm{C}$ until further analysis. The study procedures and experiments were approved by the Institutional Animal Care and Use Committee of Ewha Womans University (IACUC approval number: 19-052).

A<smiles>COc1ccc(CCC(=O)c2c(O)cc(OC3OC(CO)[C@@H](O)[C@H](O)[C@H](O)[C@H]3OCC(=O)O)cc2O)cc1O</smiles>

B

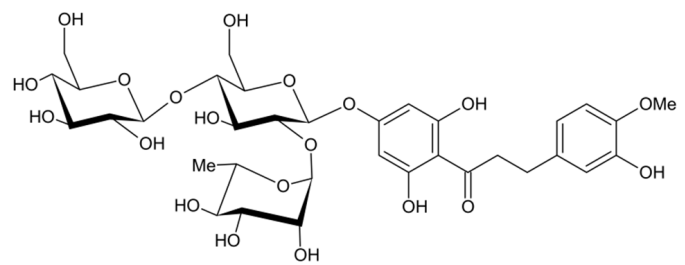

Figure 1. Structure of NHDC and GNHDC. The molecular structure of (A) NHDC and (B) GNHDC are presented. NHDC, neohesperidin dihydrochalcone; GNHDC, NHDC-O-glycoside.

Table 1. AIN-93G diet composition.

\begin{tabular}{cc}
\hline \multirow{2}{*}{ Ingredient } & AIN 93G \\
\cline { 2 - 2 } & gm \\
\hline Casein, lactic & 200 \\
\hline L-Cystine & 3 \\
\hline Corn Starch & 397 \\
\hline Sucrose & 100 \\
\hline Dextrose & 132 \\
\hline Cellulose & 50 \\
\hline Soybean Oil & 70 \\
\hline t-Butylhydroquinone & 0.014 \\
\hline AIN-93G Mineral Mix & 35 \\
\hline AIN-93 Vitamin Mix & 10 \\
\hline Choline Bitartrate & 2.5 \\
\hline Total & 1000 \\
\hline
\end{tabular}




\subsection{Oral Glucose Tolerance Test}

An oral glucose tolerance test (OGTT) was performed after 2 weeks by providing a glucose $(1 \mathrm{~g} / \mathrm{kg}$ b.w.) solution to overnight fasting mice. Their blood glucose levels were monitored at 0, 30, 60, 90, and 120 min using Accu-Check (Roche). The area under the curve (AUC) of the OGTT was calculated from the OGTT curves.

\subsection{Biochemical Analysis}

Levels of total cholesterol, high density lipoprotein (HDL)-cholesterol, and triacylglycerols were measured by commercial kits (Asan Pharmaceutical, Seoul, Korea). Low density lipoprotein (LDL) cholesterol was calculated using the Friedewald equation: LDL cholesterol $=$ Total cholesterol-HDL-cholesterol-(triacylglycerols/5). Leptin and adiponectin were measured with an enzyme-linked immunosorbent assay (ELISA) kit (Crystal Chem, Elk Grove Village, IL, USA). Non-esterified fatty acid was measured using an enzymatic colorimetric method assay (FUJIFILM Wako Pure Chemical Corporation, Osaka, Japan). Insulin was also measured using an ELISA kit (FUJIFILM Wako Pure Chemical Corporation). The degree of insulin resistance was calculated with the HOMA-IR, Homeostatic Model Assessment for Insulin Resistance index [36].

\subsection{Histological Analysis}

Subcutaneous adipose tissues were fixed with $10 \%$ formaldehyde and embedded in paraffin. Hematoxylin and eosin (H\&E) staining was performed after deparaffinizing with xylene and rehydrating. Two serial tissue sections, $5 \mu \mathrm{m}$ thick, were cut on a microtome from each paraffin-embedded specimen. Stained sections were observed with a microscope (Nikon, Tokyo, Japan) and captured. Adipocyte areas of subcutaneous adipose tissues were quantified using ImageJ (National Institutes of Health, Bethesda, MD, USA).

\subsection{Quantitative Real-Time PCR}

Samples were extracted using Trizol reagent (Invitrogen, Carlsbad, CA, USA). The concentration and quality of the RNA were checked by Nanodrop (Thermo Scientific, Waltham, MA, USA), and cDNA was produced with RevertAid reverse transcriptase (Thermo Scientific) at $42{ }^{\circ} \mathrm{C}$ for $1 \mathrm{~h}$, followed by $72{ }^{\circ} \mathrm{C}$ for $3 \mathrm{~min}$. Quantitative real-time PCR was performed using Rotor-Gene ${ }^{\circledR} \mathrm{Q}$ (Qiagen, Hilden, Germany) and 2X SYBR Green PCR master mix (Qiagen), following the manufacturer's protocol. Glyceraldehyde 3-phosphate dehydrogenase (Gapdh) was used as an internal control for both in vivo and in vitro studies. The primer sequences used are presented in Table 2.

Table 2. Primer sequences for quantitative real-time PCR.

\begin{tabular}{|c|c|c|c|}
\hline Name/GeneID & & Forward Primer $\left(5^{\prime}\right.$ to $\left.3^{\prime}\right)$ & Reverse Primer $\left(5^{\prime}\right.$ to $\left.3^{\prime}\right)$ \\
\hline $\begin{array}{c}\text { Acox1 } \\
\text { (Acyl-CoA oxidase 1) }\end{array}$ & 11430 & TTGGAAACCACTGCCACATA & AGGCATGTAACCCGTAGCAC \\
\hline $\begin{array}{l}\text { Acsl1 } \\
\text { (Acyl-CoA synthetase long-chain family member } 1)\end{array}$ & 14081 & TGCCAGAGCTGATTGACATTC & GGCATACCAGAAGGTGGTGAG \\
\hline $\begin{array}{c}C d 36 \\
\text { (Cluster of differentiation 36) } \\
\end{array}$ & 12491 & GTGCTCTCCСTTGATTCTGC & TGAGAATGCCTCCAAACACA \\
\hline $\begin{array}{c}\text { Clebp } \alpha \\
\text { (CCAAT/enhancer binding protein alpha) }\end{array}$ & 12606 & CCAAGAAGTCGGTGGACAAGA & CGGTCATTGTCACTGGTCAACT \\
\hline $\begin{array}{c}\text { Cpt1 } \alpha \\
\text { (Carnitine palmitoyltransferase } 1 \text { alpha) }\end{array}$ & 12894 & AACCCAGTGCCTTAACGATG & GAACTGGTGGCCAATGAGAT \\
\hline $\begin{array}{c}\text { Fas } \\
\text { (Fatty acid synthase) }\end{array}$ & 14104 & TGTGAGTGGTTCAGAGGCAT & TTCTGTAGTGCCAGCAAGCT \\
\hline $\begin{array}{c}I l-1 \beta \\
\text { (Interleukin } 1 \text { beta) }\end{array}$ & 16176 & ATGGCAACTGTTCCTGAACTCAACT & CAGGACAGGTATAGATTCTTTCCTTT \\
\hline $\begin{array}{c}\mathrm{Lpl} \\
\text { (Lipoprotein lipase) }\end{array}$ & 16956 & GAGTTTGACCGCCTTCCG & TCCCGTTACCGTCCATCC \\
\hline
\end{tabular}


Table 2. Cont.

\begin{tabular}{|c|c|c|c|}
\hline Name/GeneID & & Forward Primer $\left(5^{\prime}\right.$ to $\left.3^{\prime}\right)$ & Reverse Primer $\left(5^{\prime}\right.$ to $\left.3^{\prime}\right)$ \\
\hline $\begin{array}{c}M c p 1 \\
\text { (Monocyte chemoattractant protein 1) }\end{array}$ & 17224 & CTTCTGGGCCTGCTGTTCA & CCAGCCTACTCATTGGGATCA \\
\hline $\begin{array}{c}P g c 1 \alpha \\
\text { (Peroxisome proliferator-activated receptor } \\
\text { gamma coactivator } 1 \text { alpha) }\end{array}$ & 19017 & TCGAGCTGTACTTTTGTGGA & TCATACTTGCTCTTGGTGGA \\
\hline $\begin{array}{c}\text { Ppary } \\
\text { (Peroxisome proliferator-activated receptor } \\
\text { gamma) }\end{array}$ & 19016 & GAGCACTTCACAAGAAATTACC & GAACTCCATAGTGGAAGCCT \\
\hline $\begin{array}{c}\operatorname{Prdm} 16 \\
\text { (Positive regulatory domain 16) }\end{array}$ & 70673 & AGATGAACCAGGCATCCACT & TCTACGTCCTCTGGCTTTGC \\
\hline $\begin{array}{c}\text { Srebp1c } \\
\text { (Sterol regulatory element-binding protein 1) }\end{array}$ & 20787 & TAGAGCATATCCCCCAGGTG & GGTACGGGCCACAAGAAGTA \\
\hline $\begin{array}{c}\operatorname{Tnf} \alpha \\
\text { (Tumor necrosis factor alpha) }\end{array}$ & 21926 & ATGAGAAGTTCCCAAATGGC & CTCCACTTGGTGGTTTGCTA \\
\hline $\begin{array}{c}\text { Ucp1 } \\
\text { (Uncoupling protein 1) }\end{array}$ & 22227 & CCAAGCCAGGATGGTGAAC & CCAGCGGGAAGGTGATGATA \\
\hline $\begin{array}{c}\text { Glut4 } \\
\text { (Glucose transporter type 4) }\end{array}$ & 20528 & TGTTCAATCACCTGGTTGCG & CTTGGCTCCCTTCAGTTTGG \\
\hline $\begin{array}{l}\text { Gapdh } \\
\text { (Glyceraldehyde 3-phosphate dehydrogenase) }\end{array}$ & 14433 & AACTTTGGCATTGTGGAAGG & TGTGAGGGAGATGCTCAGTG \\
\hline
\end{tabular}

\subsection{Cell Culture}

A murine preadipocyte cell line, 3T3-L1, was purchased from the American Type Culture Collection (ATCC, Manassas, VA, USA). The cells were maintained in Dulbecco's modified Eagle's medium (DMEM) (Welgene, Gyeongsan, Korea), supplemented with $10 \%$ bovine calf serum (Gibco, Grand Island, NY, USA) and 1\% penicillin/streptomycin $(\mathrm{P} / \mathrm{S})$ (Invitrogen) in a $37^{\circ} \mathrm{C}$ and $5 \% \mathrm{CO}_{2}$ environment. The cells were differentiated into adipocytes in DMEM, 10\% fetal bovine serum (FBS) (Gibco), 1\% P/S, $500 \mu \mathrm{M}$ isobutylmethylxanthine (Sigma-Aldrich), $1 \mu \mathrm{M}$ dexamethasone (Sigma-Aldrich), and $10 \mu \mathrm{g} / \mathrm{mL}$ insulin (Welgene) for 2 days. After the differentiation, the adipocytes were incubated in $10 \% \mathrm{FBS}, 1 \% \mathrm{P} / \mathrm{S}$, and $1 \mu \mathrm{g} / \mathrm{mL}$ insulin for 6 days. The cells were treated with 30, 50, or $100 \mu \mathrm{M}$ NHDC or GNHDC for 8 days.

\subsection{Oil Red O Staining}

Triacylglycerol accumulation was measured by oil red O staining (Sigma-Aldrich). Differentiated adipocytes were rinsed with PBS and fixed with 10\% formaldehyde. The cells were stained with an oil red O staining solution after being washed with $60 \%$ isopropyl alcohol. The staining solution was washed away with distilled water, and the slides were subsequently dried. The stained lipid droplets were captured by an Eclipse TS100 (Nikon) before the staining solution was dissolved in 100\% isopropyl alcohol. Then, for quantification, the absorbance was recorded with a microplate reader (Molecular Device, Sunnyvale, CA, USA) at $500 \mathrm{~nm}$.

\subsection{Cell Viability Assay}

The cell viability was measured with a 3-(4,5-dimethylthiazol-2-yl)-2,5-diphenyl tetrazolium bromide (MTT) (Sigma-Aldrich) assay. The 3T3-L1 cells were seeded into 96-well plates and treated with $50 \mu \mathrm{M}$ NHDC or GNHDC for 8 days. The culture medium was removed, and the cells were treated with a medium containing $500 \mu \mathrm{g} / \mathrm{mL}$ MTT solution under $37^{\circ} \mathrm{C}$ and $5 \% \mathrm{CO}_{2}$ for $3 \mathrm{~h}$. Then, the absorbance was recorded using a microplate reader (Molecular Device) at $560 \mathrm{~nm}$. 


\subsection{Western Blotting}

The protein concentration of the differentiated adipocytes was measured with a Bradford protein assay using a Bio-Rad Protein Assay Kit (Bio-Rad, Hercules, CA, USA). The samples were denatured and separated by electrophoresis using sodium dodecyl sulphatepolyacrylamide gel electrophoresis (SDS-PAGE). Then, the protein samples were transferred to polyvinylidene fluoride membranes (Millipore, Billerica, MA, USA) and blocked with $5 \%$ bovine serum albumin or skim milk in Tris-buffered saline containing Tween 20 (TBS-T). The membranes were incubated at $4{ }^{\circ} \mathrm{C}$ overnight with primary antibodies directed against the following proteins: phosphoinositide 3 kinase (PI3K), phospho-phosphoinositide 3 kinase $(\mathrm{p}-\mathrm{PI} 3 \mathrm{~K})$, protein kinase $\mathrm{B}(\mathrm{AKT})$, phospho-protein kinase $\mathrm{B}$ (p-AKT), mammalian target of rapamycin (mTOR), phospho-mammalian target of rapamycin (p-mTOR), AMPactivated protein kinase (AMPK), and phospho-AMP-activated protein kinase ( $\mathrm{p}-\mathrm{AMPK})$ (Cell Signaling Technology, Danvers, MA, USA), with $\beta$-actin (Abcam, Cambridge, UK) as the loading control. The membranes were rinsed with TBS-T and then incubated with the corresponding secondary goat anti-mouse or anti-rabbit antibodies for $1 \mathrm{~h}$. The protein bands were detected by an enhanced chemiluminescence (ECL) reagent (Animal Genetics Inc., Suwon, Korea).

\subsection{Statistical Analysis}

All results are presented as the mean \pm standard error of the mean (SEM) and were analyzed by one-way ANOVA with a Newman-Keuls post hoc test or an unpaired Student's $t$-test. All in vitro experiments were performed at least three times. $p$-values less than 0.05 were considered significant. GraphPad Prism (GraphPad Software Inc., San Diego, CA, USA) software was used for evaluating the significance of the data. This statistical analysis is for both in vivo and in vitro studies.

\section{Results}

3.1. Effects of NHDC and GNHDC on Body Weight, Tissue Weight, Lipid Profile, and Cytokines in $d b / d b$ Mice

After 4 weeks of supplementation, the body weight and adipose tissue weight of the mice were measured (Table 3). Their final body weight tended to be reduced in both the NHDC and GNHDC supplement groups, but the change was not significant $(p>0.05)$. The body weight gain in the GNHDC group significantly decreased by $29.1 \%$ $(p<0.05)$ as compared with the Ctrl group. The subcutaneous adipose tissue weight significantly decreased by $48.4 \%$ in the NHDC group $(p<0.05)$ and by $39.6 \%$ in the GNHDC group $(p<0.05)$ as compared with the Ctrl group. The visceral adipose tissue weight was not significantly different between groups $(p>0.05)$. The total adipose tissue weightsum of the perirenal, visceral, epididymal, and subcutaneous adipose tissues-was also significantly decreased by $21.8 \%$ in the NHDC group $(p<0.05)$ and by $19.2 \%$ in the GNHDC group $(p<0.05)$.

Total cholesterol, LDL-cholesterol, HDL-cholesterol, triacylglycerols, and non-esterified fatty acid (NEFA) were analyzed to evaluate the effects of NHDC and GNHDC on the plasma lipid profile (Table 3). The total cholesterol significantly decreased by $8.3 \%$ in the GNHDC group $(p<0.05)$ as compared to the Ctrl group. Although the levels of LDLcholesterol and triacylglycerols tended to be reduced and the levels of HDL-cholesterol tended to be slightly increased in both the NHDC and GNHDC supplemented groups, these changes were not significant $(p>0.05)$. NEFA significantly decreased by $16.3 \%$ in the GNHDC group $(p<0.05)$ as compared to the Ctrl group. In addition, there was a tendency of decreasing leptin and increasing adiponectin in the GNHDC group; however, they were not significant $(p>0.05)$. Insulin was significantly increased in the NHDC group $(p<0.01)$, and it decreased slightly in the GNHDC group as compared to the Ctrl group $(p>0.05)$. There were no significant differences in HOMA-IR levels between the groups $(p>0.05)$. 
Table 3. Effects on body weight, tissue weight, plasma lipid profile, and cytokines in $\mathrm{db} / \mathrm{db}$ mice.

\begin{tabular}{|c|c|c|c|c|}
\hline & Ctrl & NHDC & GNHDC & $p$-Value \\
\hline Final body weight (g) & $37.75 \pm 1.02^{\mathrm{a}}$ & $35.23 \pm 0.64^{a}$ & $35.32 \pm 1.26^{\mathrm{a}}$ & 0.1551 \\
\hline Body weight gain (g) & $9.80 \pm 0.67^{\mathrm{a}}$ & $8.01 \pm 0.69^{a}$ & $6.95 \pm 0.79^{b}$ & 0.0314 \\
\hline Food intake (g/day) & $6.25 \pm 0.20^{a}$ & $5.90 \pm 0.20^{a}$ & $6.00 \pm 0.27^{a}$ & 0.5340 \\
\hline Water intake (mL/day) & $18.31 \pm 1.47^{\mathrm{a}}$ & $14.68 \pm 1.65^{\mathrm{a}}$ & $14.92 \pm 1.68^{\mathrm{a}}$ & 0.2216 \\
\hline Liver $(\mathrm{g})$ & $2.31 \pm 0.05^{\mathrm{a}}$ & $2.13 \pm 0.09^{a}$ & $2.08 \pm 0.12^{\mathrm{a}}$ & 0.1874 \\
\hline Subcutaneous adipose tissues (g) & $2.46 \pm 0.47^{\mathrm{a}}$ & $1.27 \pm 0.16^{\mathrm{b}}$ & $1.49 \pm 0.19^{b}$ & 0.0247 \\
\hline Visceral adipose tissues (g) & $1.22 \pm 0.07^{\mathrm{a}}$ & $1.22 \pm 0.07^{\mathrm{a}}$ & $1.12 \pm 0.04^{\mathrm{a}}$ & 0.4228 \\
\hline Total adipose tissues (g) & $5.66 \pm 0.49^{a}$ & $4.42 \pm 0.20^{b}$ & $4.57 \pm 0.24^{b}$ & 0.0299 \\
\hline Total cholesterol (mg/dL) & $159.39 \pm 3.60^{a}$ & $158.81 \pm 2.57^{\mathrm{a}}$ & $146.17 \pm 4.03^{b}$ & 0.0193 \\
\hline LDL-cholesterol (mg/dL) & $76.50 \pm 4.80^{\mathrm{a}}$ & $73.47 \pm 2.06^{\mathrm{a}}$ & $61.29 \pm 6.37^{a}$ & 0.0766 \\
\hline HDL-cholesterol (mg/dL) & $53.54 \pm 3.02^{a}$ & $53.82 \pm 2.10^{a}$ & $54.77 \pm 5.21^{\mathrm{a}}$ & 0.9205 \\
\hline Triacylglycerols (mg/dL) & $146.78 \pm 3.77^{\mathrm{a}}$ & $157.61 \pm 7.09^{\mathrm{a}}$ & $146.91 \pm 11.81^{\mathrm{a}}$ & 0.5736 \\
\hline NEFA (mEq/L) & $0.73 \pm 0.04^{\mathrm{a}}$ & $0.63 \pm 0.02^{a}$ & $0.61 \pm 0.04^{\mathrm{b}}$ & 0.0444 \\
\hline Leptin (ng/dL) & $30.05 \pm 1.24^{\mathrm{a}}$ & $31.27 \pm 1.74^{\mathrm{a}}$ & $25.67 \pm 3.37^{\mathrm{a}}$ & 0.2161 \\
\hline Adiponectin (ng/dL) & $0.54 \pm 0.02^{a b}$ & $0.50 \pm 0.02^{a}$ & $0.62 \pm 0.04^{b}$ & 0.0377 \\
\hline Insulin (ng/dL) & $1.77 \pm 0.28^{\mathrm{a}}$ & $2.95 \pm 0.36^{b}$ & $1.42 \pm 0.24^{\mathrm{a}}$ & 0.0035 \\
\hline HOMA-IR & $41.28 \pm 21.05^{\mathrm{ab}}$ & $58.86 \pm 20.98^{a}$ & $29.83 \pm 19.39^{b}$ & 0.0206 \\
\hline
\end{tabular}

All data are presented in mean \pm SEM ( $n=9$ per group) and analyzed by one-way ANOVA with a Newman-Keuls post hoc test. The $p$-values for one-way ANOVA are presented. NEFA, non-esterified fatty acid; HOMA-IR, Homeostatic Model Assessment for Insulin Resistance; Ctrl, control; NHDC, neohesperidin dihydrochalcone GNHDC, NHDC-O-glycoside. The same letter indicates no significant differences $(p>0.05)$ and different letters indicate significant differences $(p<0.05$, ANOVA).

\subsection{Effects of NHDC and GNHDC on Body Weight, Food Intake, Water Intake, Fasting Blood Glucose Levels, and OGTT in db/db Mice}

Body weight, food intake, and water intake were measured during the whole experimental period (Figure 2A-C), and they showed no significant differences between groups in every time point. Fasting blood glucose levels were monitored to evaluate the effects of NHDC and GNHDC supplementation on hyperglycemia in $\mathrm{db} / \mathrm{db}$ mice (Figure 2D). Compared to the Ctrl group, levels of fasting blood glucose were significantly decreased by both NHDC $(34.5 \%, p<0.01)$ and GNHDC $(35.5 \%, p<0.01)$ after 2 weeks of supplementation. However, this effect was reduced after 3 weeks. In addition, there was no significant difference in glucose tolerance among all groups, and the AUC for OGTT was not significantly different between the Ctrl and sweetener groups (all $p>0.05$ ) (Figure 2E).

3.3. Effects of NHDC and GNHDC on the Subcutaneous Adipocyte Area and the Gene Expressions for Lipid Metabolism in Subcutaneous Adipose Tissues

The histological changes in the subcutaneous adipose tissues were observed by H\&E staining, and the adipocyte area was measured to evaluate the effects of NHDC and GNHDC supplementation on this fat tissue (Figure 3A). The size of the lipid droplets was quantified, and they were significantly reduced by $39.4 \%$ in the NHDC $(p<0.01)$ and $39.2 \%$ in the GNHDC group $(p<0.01)$ as compared with the Ctrl group.

To evaluate the effects of NHDC and GNHDC on fatty acid uptake, lipogenesis, adipogenesis, $\beta$-oxidation, and fat browning-related genes, quantitative real-time PCR was performed. The mRNA expression levels of $C d 36$ and $L p l$ were analyzed for fatty acid uptake (Figure 3B). The mRNA expressions of $C d 36$ and $L p l$ were down-regulated by $34.6 \%$ and $46.8 \%$, respectively, in the GNHDC group ( $p<0.05$ for both) relative to the Ctrl

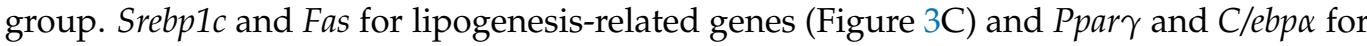


adipogenesis-related genes were analyzed (Figure 3D). Expressions of Srebp1c and Fas were decreased by $41.0 \%$ and $49.7 \%$, respectively, in the GNHDC group ( $p<0.05$ for both) as compared to the Ctrl group. Expressions of Ppar $\gamma$ and C/ebp $\alpha$ tended to be decreased by the NHDC and GNHDC supplementation, but the change was not statistically significant $(p>0.05)$.

A
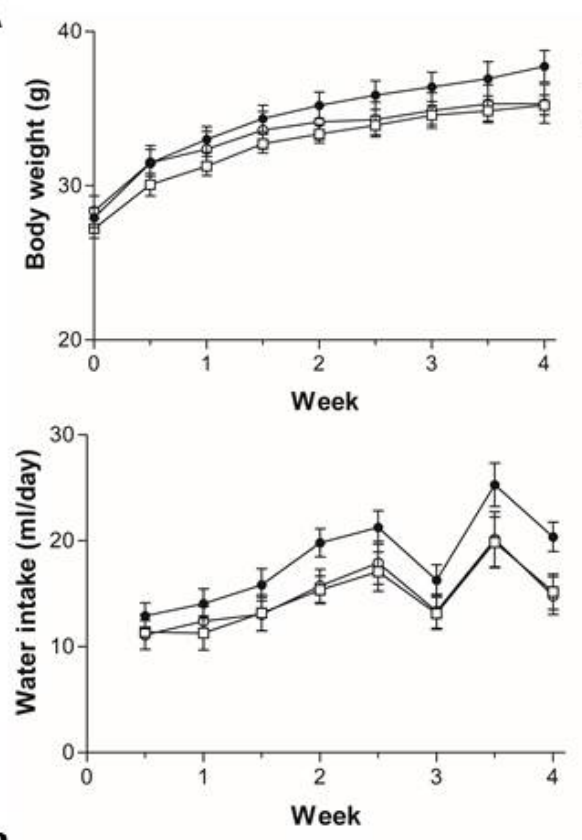

E
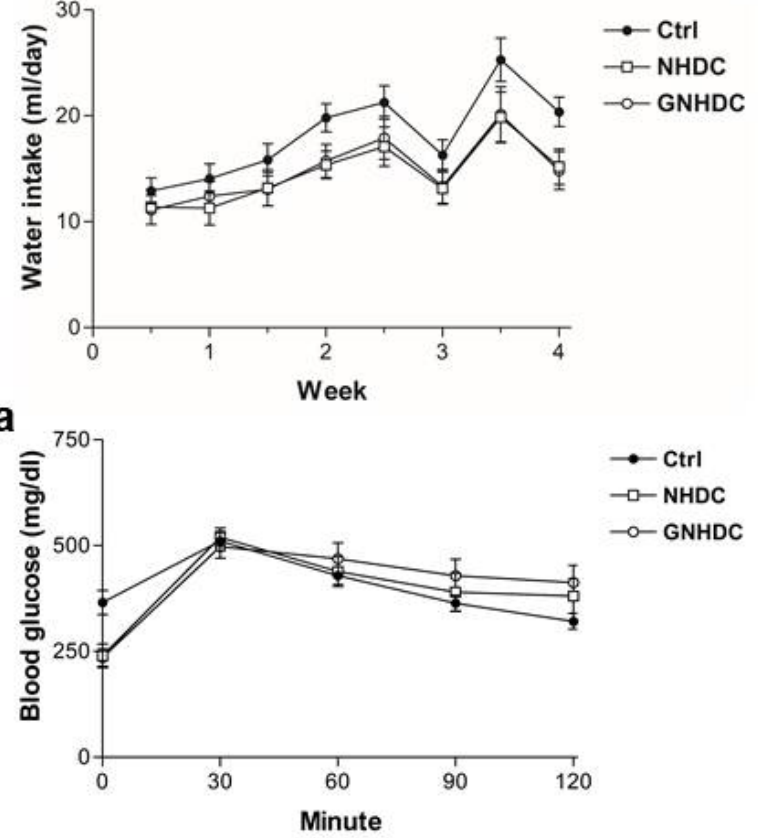

B
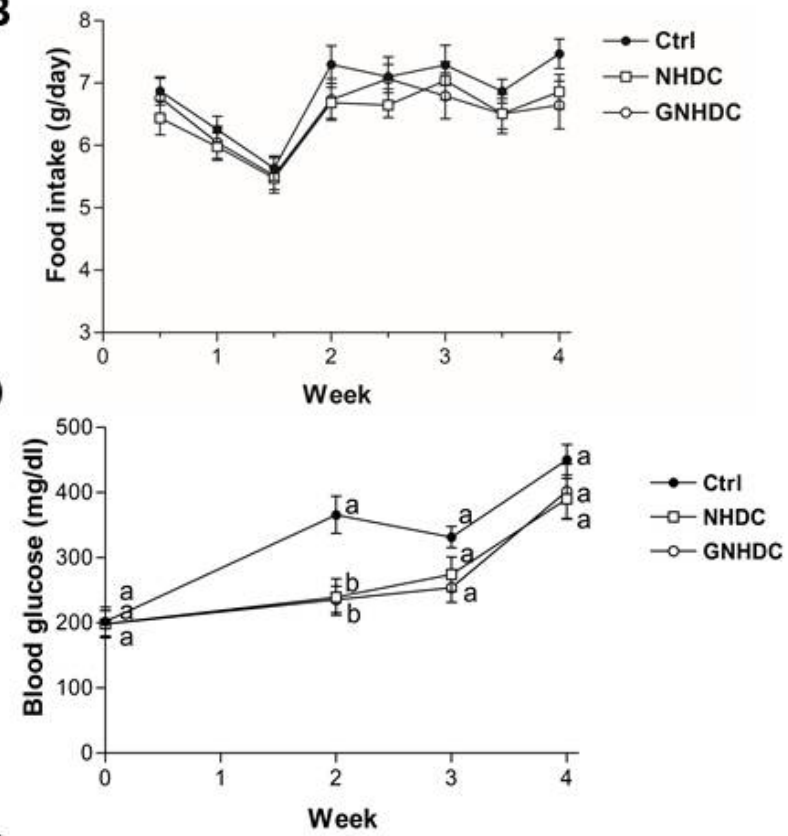

b

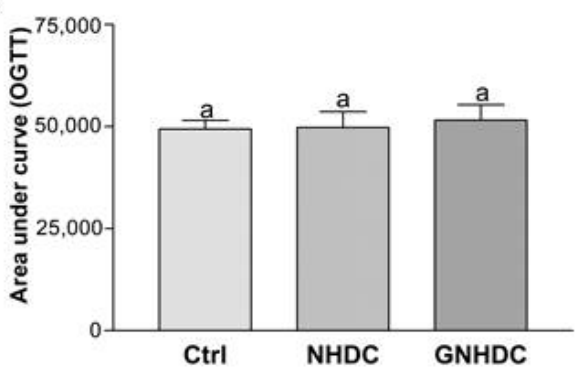

Figure 2. Effects of NHDC and GNHDC on body weight, food intake, water intake, fasting blood glucose levels, and OGTT in $\mathrm{db} / \mathrm{db}$ mice. Body weight, food intake, water intake, fasting blood glucose levels, and OGTT were analyzed in $\mathrm{db} / \mathrm{db}$ mice. (A) Body weight, (B) Food intake, and (C) Water intake, and (D) changes in fasting blood glucose levels during the experimental period. (E) (a) OGTT and (b) AUC for OGTT are presented. All data are shown as the mean \pm SEM ( $n=9$ per group) and were analyzed by one-way ANOVA with a Newman-Keuls post hoc test. OGTT, oral glucose tolerance test; AUC, area under the curve; $\mathrm{Ctrl}, \mathrm{db} / \mathrm{db}$ mice control; NHDC, $\mathrm{db} / \mathrm{db}$ mice with neohesperidin dihydrochalcone supplement; GNHDC, $\mathrm{db} / \mathrm{db}$ mice with NHDC-O-glycoside supplement. The same letter indicates no significant differences $(p>0.05)$ and different letters indicate significant differences $(p<0.05$, ANOVA).

The mRNA expression levels of the $\beta$-oxidation-related Acsl1, Acox1, and Cpt1 $\alpha$ genes were analyzed (Figure 3E). Expression of Acsl1 was up-regulated about 1.8-fold in the NHDC and GNHDC groups ( $p<0.05$ for both) as compared to the Ctrl group. Expression of Acox 1 tended to be increased by both supplements, but it was not statistically significant $(p>0.05)$. Expression of Cpt1 $\alpha$ was up-regulated about 1.5-fold in the GNHDC group $(p<0.05)$. 
A

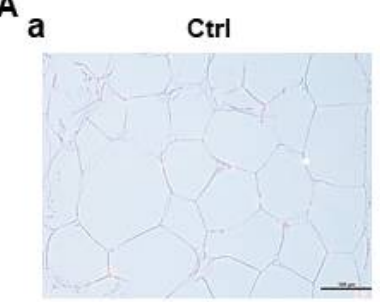

B

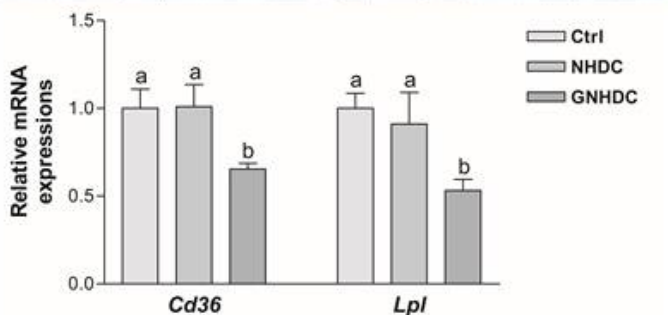

D

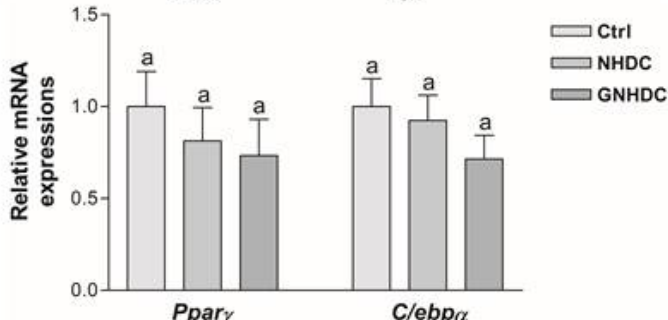

$\mathbf{F}$

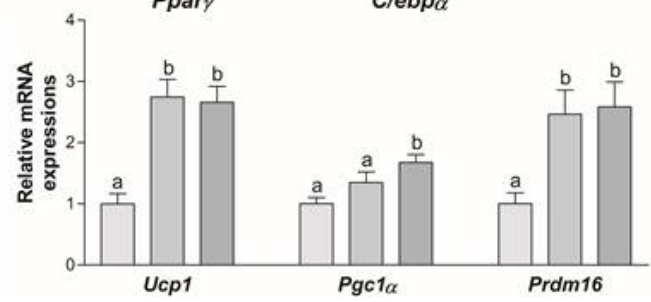

GNHDC
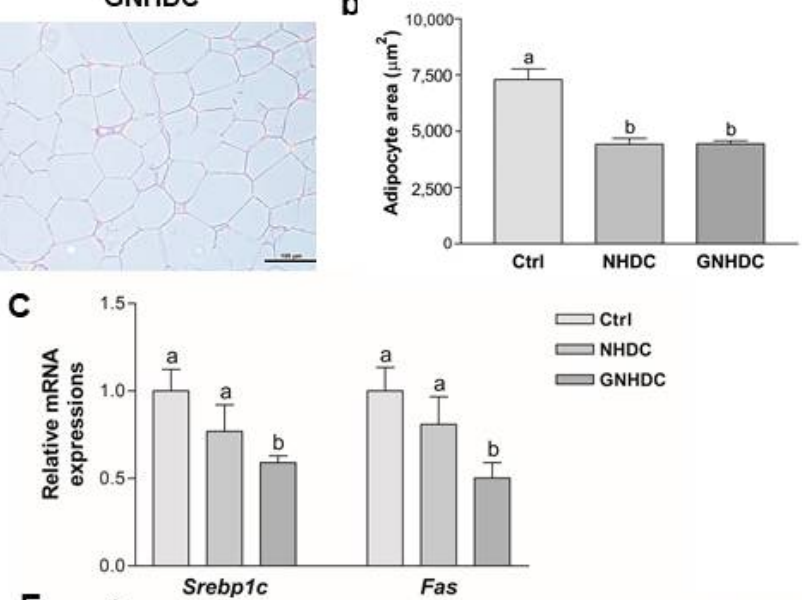

E

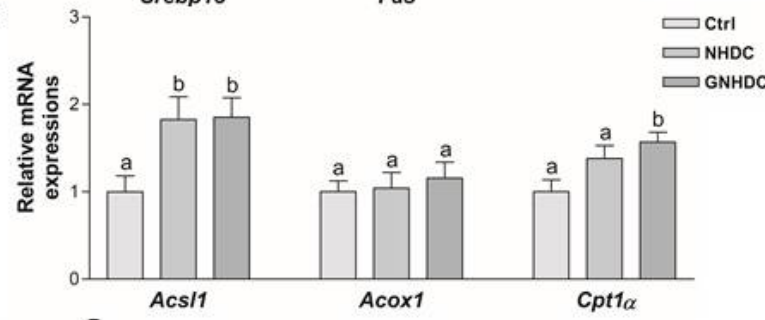

Figure 3. Effects of NHDC and GNHDC on the subcutaneous adipocyte area and the gene expressions for lipid metabolism in subcutaneous adipose tissues. Subcutaneous adipose tissues were analyzed by (A) (a) H\&E staining (magnification $200 \times$, scale bar $10 \mu \mathrm{m}$ ) with Ctrl, NHDC, and GNHDC. (b) Adipocyte area of subcutaneous adipose tissues was quantified ( $n=3$ per group). Expression levels of mRNA were analyzed for (B) fatty acid uptake-related genes, Cd36 and Lpl, (C) lipogenesis-related genes, Srebp1c and Fas, (D) adipogenesis-related genes, Ppar $\gamma$ and C/ebpo, (E) $\beta$-oxidation-related genes, Acsl1, Acox1, and Cpt1 $\alpha$, (F) fat browning-related genes, Ucp1, $P g c 1 \alpha$, and $\operatorname{Prdm16}$, and (G) the insulin-responsive glucose transporter gene, Glut4. All data (B-G) are shown as the mean \pm SEM quantified ( $n=9$ per group) and were analyzed by one-way ANOVA with a Newman-Keuls post hoc test. Acox1, acyl-CoA oxidase 1; Acsl1, acyl-CoA synthetase long-chain family member $1 ; C d 36$, cluster of differentiation 36; C/ebp $\alpha$, CCAAT/enhancer binding protein alpha; Cpt1 $\alpha$, carnitine palmitoyltransferase 1 alpha; Fas, fatty acid synthase; H\&E, hematoxylin and eosin; $\mathrm{Lpl}$, lipoprotein lipase; $P g c 1 \alpha$, peroxisome proliferator-activated receptor gamma coactivator 1 alpha; Ppary, peroxisome proliferator-activated receptor gamma; $\operatorname{Prdm16}$, positive regulatory domain 16; Srebp1c, sterol regulatory element-binding protein 1; Ucp1, uncoupling protein 1; Glut4, glucose transporter type 4; $\mathrm{Ctrl}$, $\mathrm{db} / \mathrm{db}$ mice control; NHDC, $\mathrm{db} / \mathrm{db}$ mice with neohesperidin dihydrochalcone supplement; GNHDC, db/db mice with NHDC-O-glycoside supplement. The same letter indicates no significant differences $(p>0.05)$ and different letters indicate significant differences $(p<0.05$, ANOVA).

The mRNA expression of the fat browning-related Ucp1, Pgc1 $\alpha$, and Prdm16 genes were analyzed (Figure $3 F$ ). Expression of $U c p 1$ was up-regulated in the NHDC and GNHDC group ( $p<0.01$ for both) as compared to the Ctrl group. The expression of $\operatorname{Pgc} 1 \alpha$ was up-regulated about 1.6-fold in the GNHDC group $(p<0.01)$. The expression of Prdm16 
was up-regulated about 2.4-fold in the NHDC and GNHDC groups ( $p<0.01$ for both), respectively. The mRNA expression of the Glut4 gene was analyzed. Expression of Glut4 was down-regulated by about $62.59 \%$ in the NHDC and $58.05 \%$ in the GNHDC group $(p<0.05$ for both) compared to the Ctrl group (Figure 3G).

\subsection{Effects of NHDC and GNHDC on Lipid Accumulation and Cell Viability in 3T3-L1 Cells}

After observing the significant decrease in adipose tissue weight in the NHDC and GNHDC groups in the animal study, 3T3-L1 preadipocytes were used to clarify the mechanism. To evaluate the effects of NHDC and GNHDC on triacylglycerols accumulation, oil red O staining was performed (Figure 4A). NHDC and GNHDC treatment decreased lipid droplet staining as compared to each Ctrl group (Figure 4B). It was decreased by $11.7 \%$ with $50 \mu \mathrm{M}$ NHDC $(p<0.01), 15.4 \%$ with $100 \mu \mathrm{M}$ NHDC $(p<0.01), 16.0 \%$ with $50 \mu \mathrm{M}$ GNHDC $(p<0.05)$, and $20.0 \%$ with $100 \mu \mathrm{M}$ GNHDC $(p<0.01)$ as compared to each Ctrl group, respectively. Based on the oil red $\mathrm{O}$ staining results, the lowest effective dose was 50 $\mu \mathrm{M}$ in both sweetener groups. To evaluate the cell toxicity of $50 \mu \mathrm{M}$ NHDC and GNHDC, MTT assays were performed (Figure 4C). There was no significant difference in cell viability for both sweetener treatments. Therefore, further in vitro experiments were performed with $50 \mu \mathrm{M}$ NHDC and GNHDC.

A

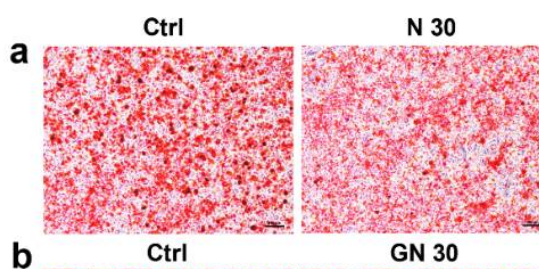

N 50

N 100
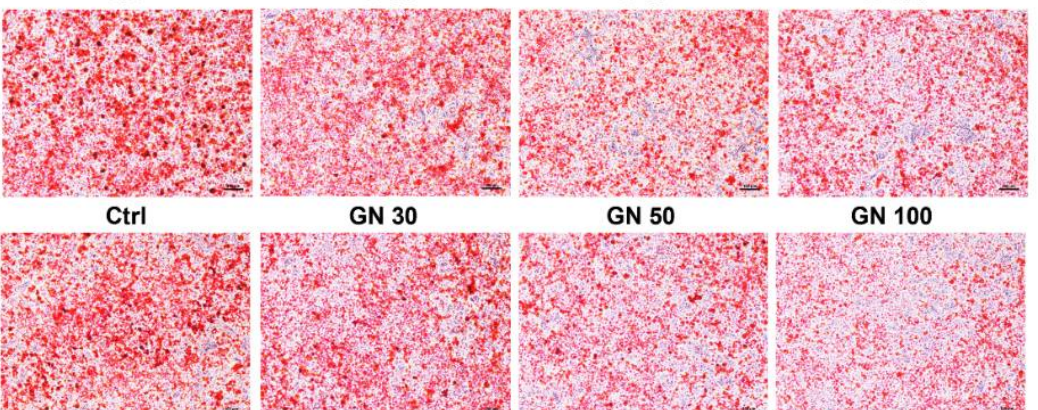

B a

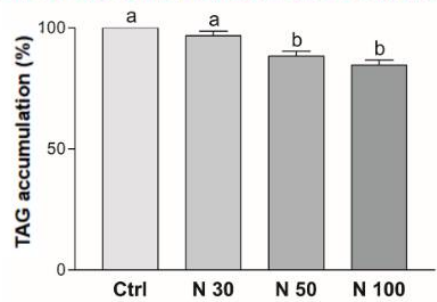

C
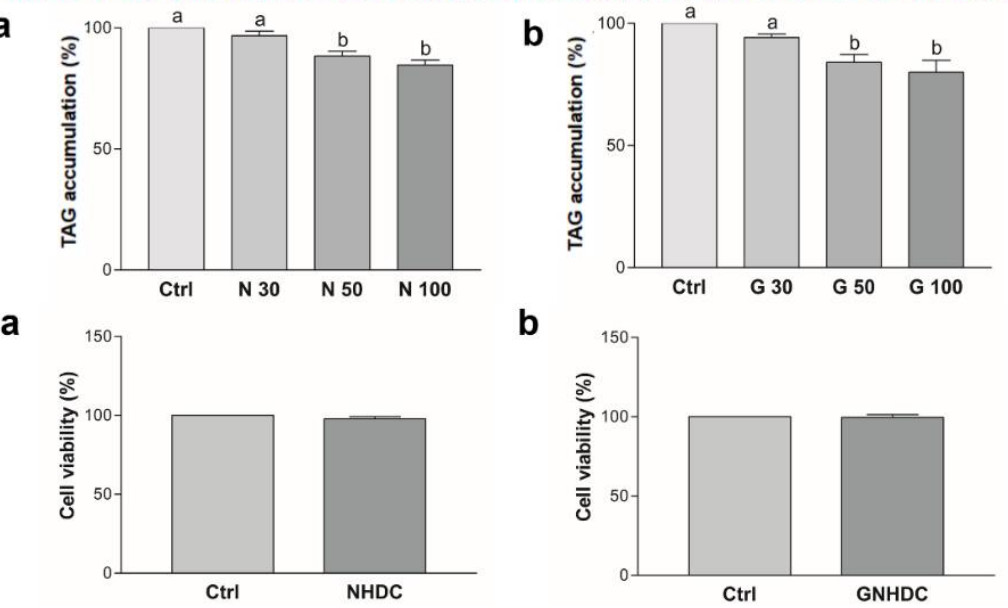

b
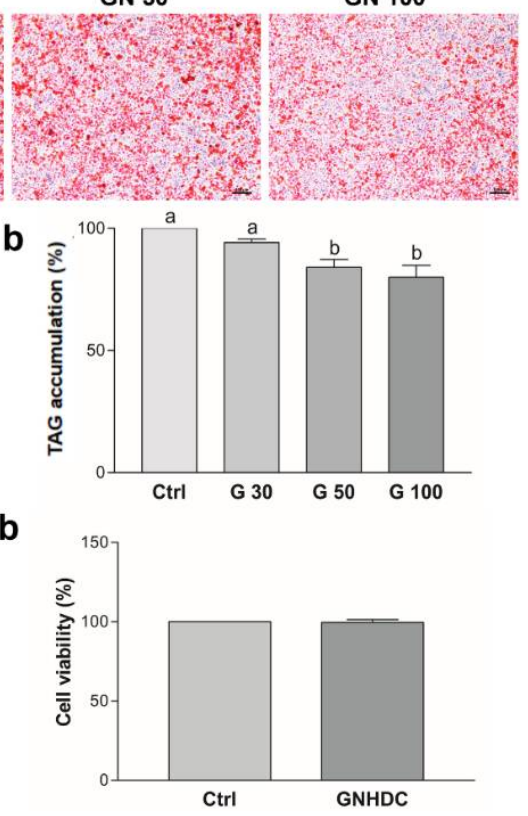

Figure 4. Effects of (a) NHDC and (b) GNHDC on lipid accumulation and cell viability in 3T3-L1 cells. Lipid accumulation was measured by (A) oil red O staining (magnification 100×, scale bar $100 \mu \mathrm{m}$ ) and (B) Triacylglycerol accumulation was quantified with Ctrl, $30 \mu \mathrm{M}, 50 \mu \mathrm{M}$, and $100 \mu \mathrm{M}$ (a) NHDC or (b) GNHDC. (C) Cell viability in 3T3-L1 cells was evaluated with $50 \mu \mathrm{M}$ (a) NHDC or (b) GNHDC for 8 days by MTT assay. All data are shown as the mean \pm SEM and were analyzed by one-way ANOVA with a Newman-Keuls post hoc test or an unpaired Student's $t$-test $(n=3)$. TAG, triacylglycerols; Ctrl, control; NHDC, neohesperidin dihydrochalcone; N 30, $30 \mu \mathrm{M} \mathrm{NHDC;} \mathrm{N} \mathrm{50,}$ $50 \mu \mathrm{M}$ NHDC; N 100, $100 \mu \mathrm{M}$ NHDC; GNHDC, NHDC-O-glycoside; GN 30, $30 \mu \mathrm{M}$ GNHDC; GN 50, $50 \mu \mathrm{M}$ GNHDC; GN 100, $100 \mu \mathrm{M}$ GNHDC. The same letter indicates no significant differences $(p>0.05)$ and different letters indicate significant differences $(p<0.05$, ANOVA). 
3.5. Effects of NHDC and GNHDC on Lipogenesis, Adipogenesis, and Proinflammatory Cytokines in 3T3-L1 Cells

To evaluate the effects of NHDC and GNHDC on lipogenesis and adipogenesis, quantitative real-time PCR was performed. The mRNA expressions of Srebp1c and Fas for lipogenesis (Figure 5A) and Pparr and C/ebp $\alpha$ for adipogenesis (Figure 5B) were analyzed. The expression of Srebp1c decreased by $56.5 \%$ with NHDC $(p<0.01)$ and by $48.5 \%$ with the GNHDC treatment $(p<0.01)$ as compared to each Ctrl group. The expression of Fas decreased by $55.3 \%$ with NHDC $(p<0.01)$ and by $51.8 \%$ with the GNHDC treatment $(p<0.01)$ as compared to each Ctrl group. The mRNA expression of Ppar $\gamma$ decreased by $6.2 \%$ with NHDC $(p<0.01)$ and by $27.9 \%$ with the GNHDC treatment $(p<0.01)$ as compared to each Ctrl group. The mRNA expression of C/ebp $\alpha$ decreased by $21.2 \%$ with NHDC $(p<0.05)$ and by $44.2 \%$ with the GNHDC treatment $(p<0.01)$ as compared to each Ctrl group.

A

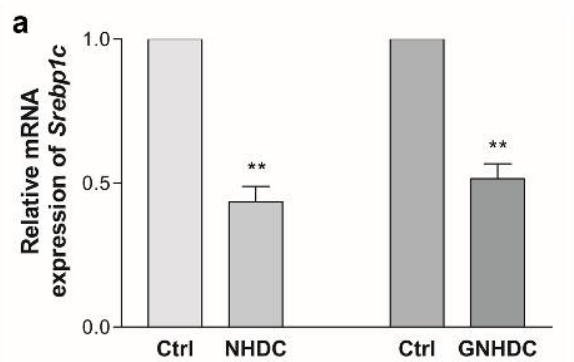

B a

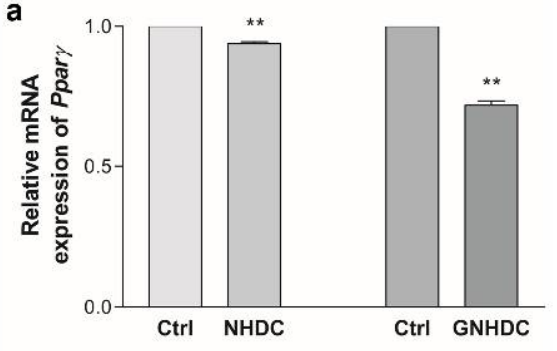

b

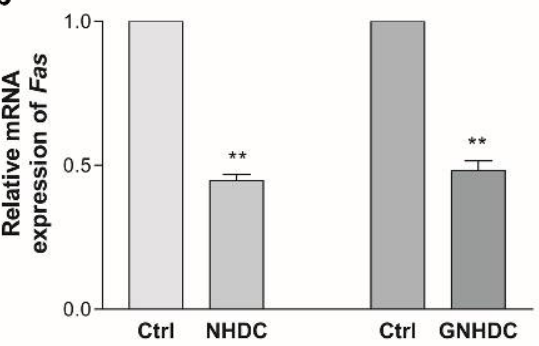

b

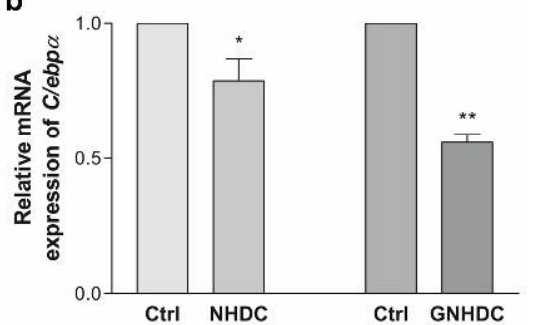

$C_{\text {a }}$
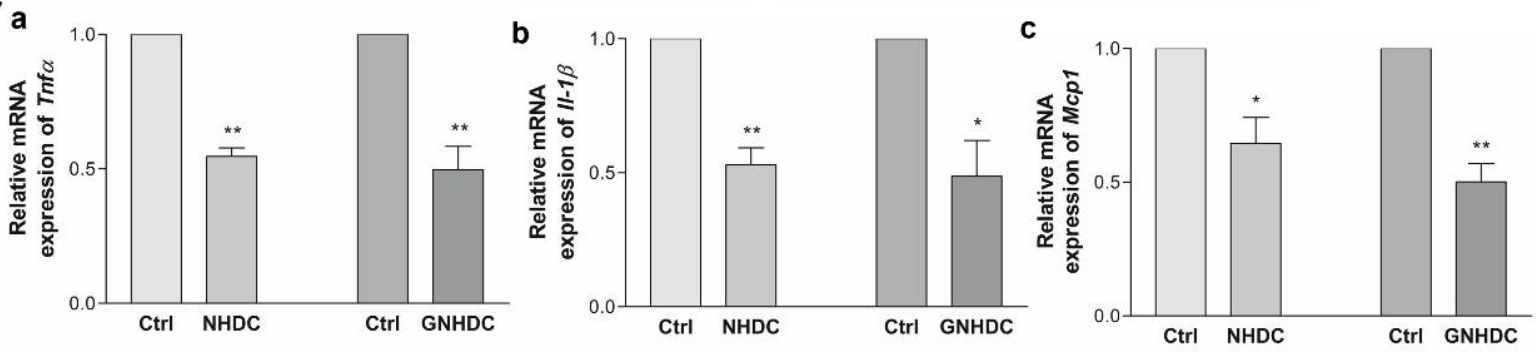

Figure 5. Effects of NHDC and GNHDC on lipogenesis, adipogenesis, and proinflammatory cytokines in 3T3-L1 cells. Expression of mRNA was analyzed for (A) lipogenesis-related genes, (a) Srebp1c and (b) Fas, (B) adipogenesis-related genes, (a) Ppar $\gamma$ and (b) C/ebpa, (C) proinflammatory cytokinesrelated genes, (a) Tnfa, (b) Il-1 $\beta$, and (c) Mcp1. All data are shown as the mean $\pm \mathrm{SEM}$ and were analyzed by an unpaired Student's $t$-test $(n=3-4)$. Each asterisk indicates significant difference as compared to Ctrl; ${ }^{*}(p<0.05)$ and ${ }^{* *}(p<0.01)$. C/ebp $\alpha$, CCAAT/enhancer binding protein alpha;

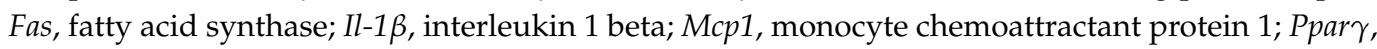
peroxisome proliferator-activated receptor gamma coactivator 1 alpha; Srebp1c, sterol regulatory element-binding protein 1; Tnfa, tumor necrosis factor alpha; Ctrl, control; NHDC, neohesperidin dihydrochalcone; GNHDC, NHDC-O-glycoside.

Next, the effects of both sweeteners on proinflammatory cytokines, including Tnf $\alpha$, Il-1 $\beta$, and Mcp1, were evaluated (Figure 5C). The mRNA expression of Tnf $\alpha$ decreased by $45.4 \%$ with NHDC $(p<0.01)$ and by $50.3 \%$ with the GNHDC treatment $(p<0.01)$ as 
compared to each Ctrl group. The expression of $I l-1 \beta$ decreased by $47.0 \%$ with NHDC $(p<0.01)$ and by $51.3 \%$ with the GNHDC treatment $(p<0.05)$ as compared to each Ctrl group. The expression of Mcp 1 decreased by 35.5\% with NHDC $(p<0.05)$ and by $49.9 \%$ with the GNHDC $(p<0.01)$ treatment.

\subsection{Effects of NHDC and GNHDC on the PI3K/AKT/mTOR Pathway and AMPK in 3T3-L1 Cells}

To evaluate the effects of NHDC and GNHDC on the PI3K/AKT/mTOR pathway, western blot analysis was performed (Figure 6). In the present study, the expression of p-PI3K/PI3K decreased by $41.0 \%$ with NHDC $(p<0.05)$ and by $19.3 \%$ with the GNHDC treatment $(p<0.01)$ as compared to each Ctrl group. The expression of $\mathrm{p}-\mathrm{AKT} / \mathrm{AKT}$ decreased by $26.8 \%$ with NHDC $(p<0.05)$ and by $46.1 \%$ with the GNHDC treatment $(p<0.01)$. The expression of $\mathrm{p}-\mathrm{mTOR} / \mathrm{mTOR}$ decreased by $35.6 \%$ with NHDC $(p<0.01)$ and by $12.7 \%$ with the GNHDC treatment $(p<0.01)$. In the present study, expression of p-AMPK/AMPK increased by about $349.3 \%$ with NHDC $(p<0.05)$ and by $248.3 \%$ with the GNHDC treatment $(p<0.01)$.

A

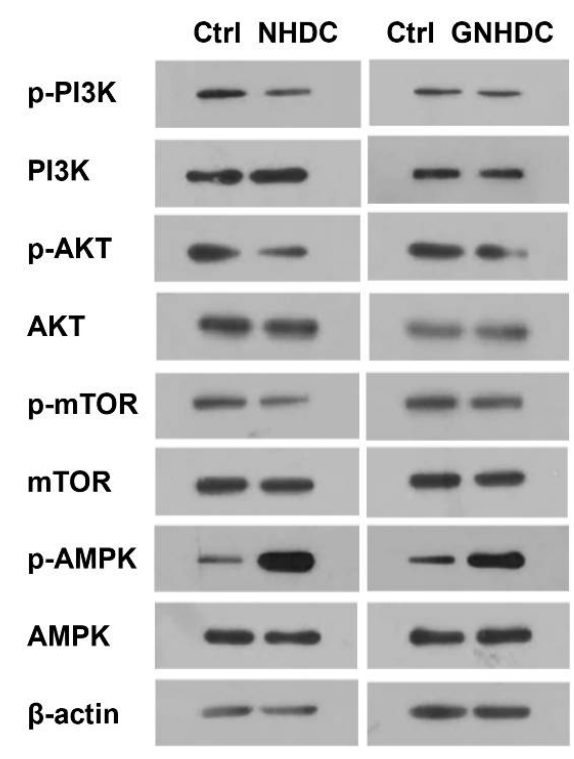

C

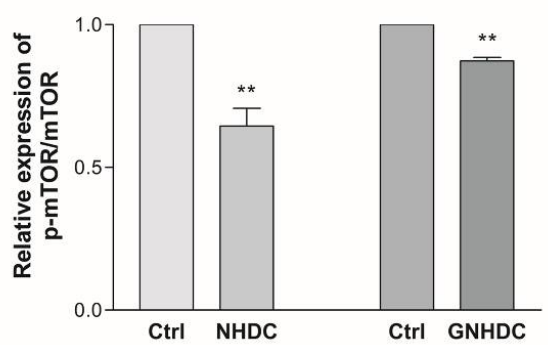

B

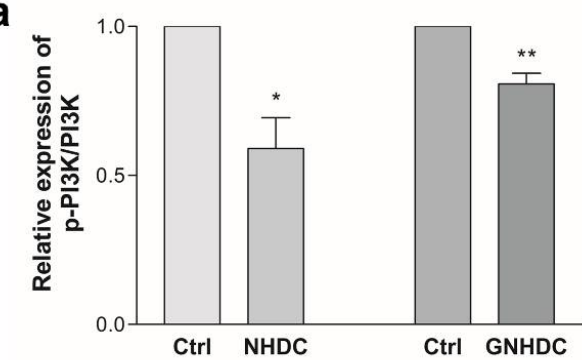

b

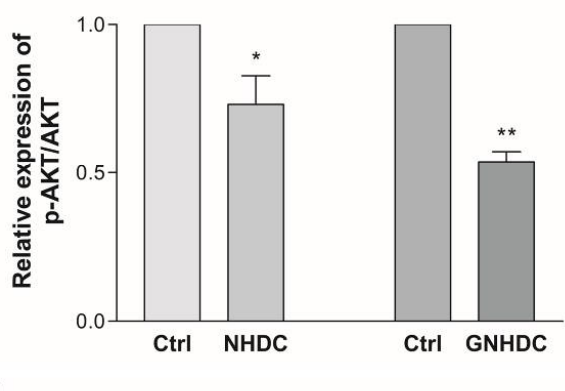

d

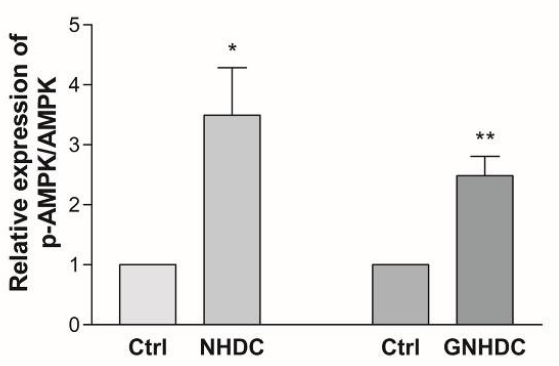

Figure 6. Effects of NHDC and GNHDC on the PI3K/AKT/mTOR pathway and AMPK in 3T3L1 cells. The expression of protein was analyzed for the PI3K/AKT/mTOR pathway and AMPK. (A) Representative blots are presented; (B) Quantification of expression of (a) p-PI3K/PI3K, (b) p$\mathrm{AKT} / \mathrm{AKT}$, (c) p-mTOR/mTOR, and (d) p-AMPK/AMPK. All data are shown as the mean $\pm \mathrm{SEM}$ and were analyzed by an unpaired Student's $t$-test $(n=3)$. Each asterisk indicates significant difference as compared to $\mathrm{Ctrl} ;{ }^{*}(p<0.05)$ and ${ }^{* *}(p<0.01)$. AKT, protein kinase B; AMPK, AMP-activated protein kinase; mTOR, mammalian target of rapamycin; PI3K, phosphoinositide 3 kinase; p-AKT, phospho-protein kinase B; p-AMPK, phospho-AMP-activated protein kinase; p-mTOR, phosphomammalian target of rapamycin; p-PI3K, phospho-phosphoinositide 3 kinase; Ctrl, control; NHDC, neohesperidin dihydrochalcone; GNHDC, NHDC-O-glycoside. 


\section{Discussion}

We selected the treatment dose based on previous studies and preliminary data. Previously, NHDC was used at 100-200 mg/kg b.w. [26,37-39] and no observed effect level (NOAEL) of NHDC was reported for $750 \mathrm{mg} / \mathrm{kg}$ b.w. in rats [40]. The Scientific Committee for Food of the European Community allocated NOAEL of $500 \mathrm{mg} / \mathrm{kg}$ b.w. and declared $5 \mathrm{mg} / \mathrm{kg}$ b.w. as an acceptable daily intake (ADI) level for NHDC [41]. NHDC is a semi-natural sweetener since it is naturally presented as neohesperidin, its parent flavone, before it is processed to NHDC [19]. NHDC is used as an ingredient in numerous processed foods, including drinks [19]. More than 90\% of 14C-labeled NHDC was found to be excreted in the urine in a rat study due to its low rate of metabolism. Due to the low bioavailability of NHDC, it was suggested to provide not more than 1/1000 calories compared with an equivalent amount of sucrose [24].

Levels of water intake were decreased in both the NHDC and GNHDC groups, which suggested the anti-diabetic effects of these two sweeteners by alleviating polydipsia, a primary symptom of diabetes mellitus [42]. Previous studies have described the effects of alternative sweeteners on blood glucose levels [43,44]. Consistently, blood glucose levels were significantly decreased in supplemented groups in the second week of the experiment, whereas significant differences were not seen after the third week in the present study. Plasma insulin was unexpectedly higher in the NHDC group than in the Ctrl group. Insulin levels could be increased due to insulin resistance or a compensation for increased blood glucose in the sweetener groups. These results suggest that both sweeteners exhibit anti-diabetic effects in early diabetes. Glycosides are known for their anti-diabetic effects in several studies $[45,46]$. Several glycosidic substances suppress glucose reabsorption by inhibiting a normal transport of glucose via SGLT [45]. SGLT allows glucose to be transported into cells [47]. Conversely, SGLT1 and SGLT2 inhibitors prevent the reabsorption of glucose in the kidney or gut. Previous studies reported that blood glucose levels were lowered by SGLT1/SGLT2 inhibitors [48,49].

Although NHDC and GNHDC showed insignificant effects on regulating blood glucose levels at the end of the experiment, both sweeteners tended to decrease the body weight gain in $\mathrm{db} / \mathrm{db}$ mice. The calories provided by the supplements used in this study were negligible considering the characteristic of intense sweeteners, which produce no or low calories [50]. NHDC produces about $2 \mathrm{kcal} / \mathrm{g}$ [17]. Food intake levels were not significantly changed in both sweetener groups as compared to the Ctrl group. This result suggests that the decreased body weight gain caused by these sweeteners was not due to decreased food intake.

All lipogenesis, adipogenesis, and proinflammatory cytokine-related genes were significantly down-regulated by NHDC or GNHDC treatment. Subcutaneous adipose tissue weights and adipocyte areas showed a significant decrease with NHDC and GNHDC supplementation. However, visceral fats have been targeted more than subcutaneous fats in terms of diabetes and obesity [51,52]. Visceral adipose tissue is related to type 2 diabetes mellitus [53] and dyslipidemia [54,55]. There is a link between visceral adipose tissue and the liver, which involves glucose metabolism [56]. In the present study, visceral adipose tissues and liver weight tended to decrease in the GNHDC group as compared to the Ctrl group, but this was not significant. This result suggests that NHDC and GNHDC improve lipogenesis, adipogenesis, $\beta$-oxidation, and fat browning while having little effects on regulating blood glucose levels.

A further in vitro study investigated the PI3K/AKT/mTOR pathway to understand the mechanism of the anti-obesity effects identified in the in vivo study. The activation of the PI3K/AKT/mTOR pathway increases cell proliferation and lipid synthesis through lipogenesis and adipogenesis [57]. The PI3K/AKT/mTOR pathway regulates lipogenesis via SREBP1C [57] as well as cell proliferation and glucose homeostasis [58]. In particular, the effects of NHDC and GNHDC on lipogenesis were more remarkable than their effects on adipogenesis in 3T3-L1 cells. Lipogenesis is defined as a process of fatty acid synthesis in the liver or adipose tissues [7]. Circulating free fatty acids are the main substrates 
used for the biosynthesis of long chain fatty acids and lipid accumulation. In this process, SREBP1C contributes to the synthesis of fat in adipose tissues [59]. On the other hand, the expression of mTOR is inhibited by the up-regulation of AMPK [60]. Previously, it was reported that sweeteners suppressed the PI3K/AKT/mTOR pathway and activated AMPK activation [61-63]. Consistently, the present study demonstrated that these sweeteners regulated this lipogenic pathway.

Several lipid mechanisms have been connected to each other by regulating fat accumulation and loss. Adipogenesis regulators are linked to fat browning [64]. For example, PPAR $\gamma$ is highly activated in subcutaneous adipose tissues [65], and it affects fat browning-related genes by stimulating the UCP enhancer during cell differentiation and by up-regulating adipocyte-specific UCP1 expression [66]. PGC1 $\alpha$ is involved in a wide range of biological mechanisms such as adipogenesis, triacylglycerols metabolism, $\beta$-oxidation, and fat browning [67]. PGC1 $\alpha$ is a binding partner of PPAR $\gamma$ in brown adipose tissue (BAT), and it increases PPAR $\gamma$ transcriptional activity to stimulate brown adipocyte differentiation. In addition, PGC1 $\alpha$ activates UCP1 transcription and increases thermogenesis in cold environments $[10,68]$. Moreover, PGC1 $\alpha$ up-regulates $\beta$-oxidation-related markers, including ACSL and CPT1 $\alpha$, which are crucial for the regulation of fatty acid in BAT.

A correlation between fat browning and glycosides has recently been reported. As mentioned earlier, glycosidic substances inhibited glucose reabsorption by suppressing SGLT's glucose transport. Empagliflozin, known as an SGLT2 inhibitor, regulates fat browning-related gene expression [69] such as UCP1, cell death-inducing DNA fragmentation factor alpha-like effector A (CIDEA), PRDM16, and PGC1 $\alpha$. This present study also found that GNHDC significantly up-regulated fat browning markers. The glycosidic structure of the sweetener activated fat browning [70], which may be one of anti-obesity mechanisms of GNHDC. Thus, NHDC and GNHDC exerted an anti-obesity effect by increasing fat browning through the regulation of AMPK targets such as PGC-1 $\alpha$, PRDM16, and UCP1.

Interestingly, GNHDC exerted a better fat reduction effect than NHDC did. Previous studies have reported that glycosides of the flavonoid group could suppress lipid accumulation and related gene expressions in in vivo animal studies. Quercetin from flavonol and its glycoside molecules down-regulated adipogenesis and up-regulated browning markers through AMPK activation. Body weight gain and lipid accumulation were decreased in adipose tissues by the glycoside groups [71]. That study demonstrated that the differences in efficiency were due to bioavailability or conjugated forms. The bioavailability of glycosides are important for their metabolites [72]. From this perspective, the major metabolites of NHDC are hesperetin dihydochalcone and hesperetin [73]; however, for GNHDC, it remains unclear. Flavonoid glycosides from seabuckthorn leaves reduced the size of the lipid droplets in white adipose tissue [74], and kaempferol glycosides down-regulated the mRNA expression levels of Ppar $\gamma$ and Srebp1c [29]. It is noteworthy that the present study showed a higher efficiency of glycosidic sweetener on lipogenesis, and that adipogenesis occurred in vivo.

Regarding glycoside absorption, the structure of glycosidic compounds affected glucose uptake via SGLT and the glucose transporter (GLUT) in human intestinal epithelial Caco-2 cells [75]. This study illustrated that the molecular structures and the number of sugars added to the flavonoid compound affected its absorption. Several organs such as the liver, intestines, and kidney are involved in the metabolic processing of glycosides [72]. For these reasons, metabolic processes may explain their higher efficiency in animal studies than in in vitro studies. However, the underlying mechanism of GNHDC has not been elucidated. The pharmacokinetic parameters of the bioavailability and the metabolites of the glycosidic sweetener need to be investigated in future studies.

\section{Conclusions}

NHDC and GNHDC caused a reduction of fat and lipid accumulation in $\mathrm{db} / \mathrm{db}$ mice and 3T3-L1 cells. Both sweeteners regulated the expression of genes involved in fatty acid 
uptake, lipogenesis, adipogenesis, $\beta$-oxidation, and fat browning in vivo. The sweeteners down-regulated genes involved in lipogenesis and adipogenesis, proinflammatory cytokines, and the PI3K/AKT/mTOR pathway, and they up-regulated AMPK phosphorylation in vitro. These results were more significant with GNHDC. It is necessary to further examine the mechanism of glycosides in terms of regulating glucose and lipid metabolism. Thus, NHDC and its glycosides, GNHDC, have the promising potential of reducing subcutaneous fat and lipid accumulation through the modulation of the PI3K/AKT/mTOR and AMPK pathway-related molecular markers.

Author Contributions: Conceptualization, J.A.M., Y.K. (Yang Kim) and Y.K. (Yuri Kim); methodology, M.K., Y.K. (Yerin Kim), J.L., J.A.M., Y.K. (Yang Kim) and Y.K. (Yuri Kim); validation, M.K. and Y.K. (Yuri Kim); formal analysis, M.K.; investigation, Y.K. (Yuri Kim); writing-original draft preparation, M.K., Y.K. (Yerin Kim) and Y.K. (Yuri Kim); writing-review and editing, Y.K. (Yang Kim), J.A.M. and Y.K. (Yuri Kim); visualization, M.K. and Y.K. (Yerin Kim); supervision, Y.K. (Yuri Kim); project administration, Y.K. (Yuri Kim); funding acquisition, Y.K. (Yuri Kim). All authors have read and agreed to the published version of the manuscript.

Funding: This research was funded by the Korea Institute of Planning and Evaluation for Technology in Food, Agriculture, Forestry (IPET) through the Innovative Food Product and Natural Food Materials Development Program, funded by the Ministry of Agriculture, Food and Rural Affairs (MAFRA), 119020-03-2-HD040.

Institutional Review Board Statement: The study was conducted according to the guidelines of the National Institutes of Health (NIH Publications No. 8023, revised 1978) and was approved by the Institutional Animal Care and Use Committee of Ewha Womans University (IACUC approval number: 19-052).

Data Availability Statement: Most of the data can be found in the manuscript, and further data are available on reasonable request from the corresponding author.

Conflicts of Interest: The authors declare no conflict of interest.

Sample Availability: Samples of the compounds are not available from the authors.

\section{References}

1. World Health Organization. Obesity and Overweight. Available online: https://www.who.int/news-room/fact-sheets/detail/ obesity-and-overweight/ (accessed on 16 December 2020).

2. World Health Organization. Obesity: Preventing and Managing the Global Epidemic; World Health Organization: Geneva, Switzerland, 2000.

3. Chan, J.M.; Rimm, E.B.; Colditz, G.A.; Stampfer, M.J.; Willett, W.C. Obesity, fat distribution, and weight gain as risk factors for clinical diabetes in men. Diabetes Care 1994, 17, 961-969. [CrossRef] [PubMed]

4. Prospective Studies Collaboration. Body-mass index and cause-specific mortality in 900,000 adults: Collaborative analyses of 57 prospective studies. Lancet 2009, 373, 1083-1096. [CrossRef]

5. Hamer, M.; Stamatakis, E. Metabolically Healthy Obesity and Risk of All-Cause and Cardiovascular Disease Mortality. J. Clin. Endocrinol. Metab. 2012, 97, 2482-2488. [CrossRef] [PubMed]

6. Sowers, J.R. Obesity as a cardiovascular risk factor. Am. J. Med. 2003, 115, 37-41. [CrossRef]

7. El Hafidi, M.; Buelna-Chontal, M.; Sánchez-Muñoz, F.; Carbó, R. Adipogenesis: A Necessary but Harmful Strategy. Int. J. Mol. Sci. 2019, 20, 3657. [CrossRef] [PubMed]

8. Jones, P.M.; Bennett, M.J. Disorders of mitochondrial fatty acid $\beta$-oxidation. In Biomarkers in Inborn Errors of Metabolism, 1st ed.; Garg, U., Smith, L., Eds.; Elsevier: Amsterdam, The Netherlands, 2017; pp. 87-93. [CrossRef]

9. Bartelt, A.; Heeren, J. Adipose tissue browning and metabolic health. Nat. Rev. Endocrinol. 2014, 10, 24-36. [CrossRef]

10. Harms, M.; Seale, P. Brown and beige fat: Development, function and therapeutic potential. Nat. Med. 2013, 19, 1252-1263. [CrossRef]

11. Wittekind, A.; Walton, J. Worldwide trends in dietary sugars intake. Nutr. Res. Rev. 2014, 27, 330-345. [CrossRef]

12. Duffey, K.J.; Popkin, B.M. Shifts in Patterns and Consumption of Beverages Between 1965 and 2002. Obesity 2007, 15, 2739-2747. [CrossRef]

13. Bray, G.A.; Nielsen, S.J.; Popkin, B.M. Consumption of high-fructose corn syrup in beverages may play a role in the epidemic of obesity. Am. J. Clin. Nutr. 2004, 79, 537-543. [CrossRef]

14. World Health Organization. Executive summary. In Guideline: Sugars Intake for Adults and Children; World Health Organization: Geneva, Switzerland, 2015; pp. 3-7. 
15. Keller, A.; Della Torre, S.B. Sugar-Sweetened Beverages and Obesity among Children and Adolescents: A Review of Systematic Literature Reviews. Child. Obes. 2015, 11, 338-346. [CrossRef] [PubMed]

16. Malik, V.S.; Pan, A.; Willett, W.C.; Hu, F.B. Sugar-sweetened beverages and weight gain in children and adults: A systematic review and meta-analysis. Am. J. Clin. Nutr. 2013, 98, 1084-1102. [CrossRef] [PubMed]

17. Glória, M. Sweeteners/Others. In Encyclopedia of Food Sciences and Nutrition, 2nd ed.; Caballero, B., Finglas, P., Toldrá, F., Eds.; Academic Press: Cambridge, UK, 2003; pp. 5696-5699.

18. Edwards, C.H.; Rossi, M.; Corpe, C.P.; Butterworth, P.J.; Ellis, P.R. The role of sugars and sweeteners in food, diet and health: Alternatives for the future. Trends Food Sci. Technol. 2016, 56, 158-166. [CrossRef]

19. Food and Drug Administration. GRAS Notice (GRN) No. 902: Neohesperidin Dihydrochalcone; HealthTech BioActives, S.L.U.: Beniel, Spain, 2019; pp. 9-42.

20. Horowitz, R.M.; Gentili, B. Dihydrochalcone Derivatives and Their Use as Sweetening Agents. U.S. Patent 3,087,821, 30 April 1963

21. Hattori, S.; Shimokoriyama, M.; Kanao, M. Studies on Flavanone Glycosides. IV. The Glycosides of Ripe Fruit Peel and Flower Petals of Citrus Aurantium L. J. Am. Chem. Soc. 1952, 74, 3614-3615. [CrossRef]

22. Horowitz, R.M.; Gentili, B. Taste and structure in phenolic glycosides. J. Agric. Food Chem. 1969, 17, 696-700. [CrossRef]

23. Harborne, J.B. Biochemistry of phenolic compounds. In Biochemistry of Phenolic Compounds; Academic Press: New York, NY, USA, 1964; pp. 545-571.

24. O'Brien-Nabors, L. Alternative Sweeteners, 3rd ed.; Marcel Dekker: New York, NY, USA, 2001; pp. 87-96. [CrossRef]

25. Han, G.E.; Kang, H.-T.; Chung, S.; Lim, C.; Linton, J.A.; Lee, J.-H.; Kim, W.; Kim, S.-H.; Lee, J.H. Novel Neohesperidin Dihydrochalcone Analogue Inhibits Adipogenic Differentiation of Human Adipose-Derived Stem Cells through the Nrf2 Pathway. Int. J. Mol. Sci. 2018, 19, 2215. [CrossRef]

26. Shi, Q.; Song, X.; Fu, J.; Su, C.; Xia, X.; Song, E.; Song, Y. Artificial sweetener neohesperidin dihydrochalcone showed antioxidative, anti-inflammatory and anti-apoptosis effects against paraquat-induced liver injury in mice. Int. Immunopharmacol. 2015, 29, 722-729. [CrossRef]

27. Singh, R.G. Chemotaxonomy of Medicinal Plants: Possibilities and Limitations. In Natural Products and Drug Discovery, 1st ed.; Mandal, S., Mandal, V., Konishi, T., Eds.; Elsevier: Amsterdam, The Netherlands, 2018; p. 127. [CrossRef]

28. Yang, R.-M.; Liu, F.; He, Z.-D.; Ji, M.; Chu, X.-X.; Kang, Z.-Y.; Cai, D.-Y.; Gao, N.-N. Anti-obesity effect of total phenylpropanoid glycosides from Ligustrum robustum Blume in fatty diet-fed mice via up-regulating leptin. J. Ethnopharmacol. 2015, 169, 459-465. [CrossRef]

29. Zang, Y.; Zhang, L.; Igarashi, K.; Yu, C. The anti-obesity and anti-diabetic effects of kaempferol glycosides from unripe soybean leaves in high-fat-diet mice. Food Funct. 2015, 6, 834-841. [CrossRef]

30. Kerru, N.; Singh-Pillay, A.; Awolade, P.; Singh, P. Current anti-diabetic agents and their molecular targets: A review. Eur. J. Med. Chem. 2018, 152, 436-488. [CrossRef]

31. Choi, J.-M.; Yoon, B.-S.; Lee, S.-K.; Hwang, J.-K.; Ryang, R. Antioxidant Properties of Neohesperidin Dihydrochalcone: Inhibition of Hypochlorous Acid-Induced DNA Strand Breakage, Protein Degradation, and Cell Death. Biol. Pharm. Bull. 2007, 30, 324-330. [CrossRef] [PubMed]

32. Jolivalt, C.; Lee, C.; Beiswenger, K.; Smith, J.; Orlov, M.; Torrance, M.; Masliah, E. Defective insulin signaling pathway and increased glycogen synthase kinase- 3 activity in the brain of diabetic mice: Parallels with Alzheimer's disease and correction by insulin. J. Neurosci. Res. 2008, 86, 3265-3274. [CrossRef] [PubMed]

33. Kobayashi, K.; Forte, T.M.; Taniguchi, S.; Ishida, B.Y.; Oka, K.; Chan, L. The db/db mouse, a model for diabetic dyslipidemia: Molecular characterization and effects of western diet feeding. Metabolism 2000, 49, 22-31. [CrossRef]

34. Herbreteau, V.; Jittapalapong, S.; Rerkamnuaychoke, W.; Chaval, Y.; Cosson, J.-F.; Morand, S. Protocols for Field and Laboratory Rodent Studies; Kasetsart University: Bangkok, Thailand, 2011; pp. 5-46.

35. Bagchi, D.P.; MacDougald, O.A. Identification and Dissection of Diverse Mouse Adipose Depots. J. Vis. Exp. 2019, 149. [CrossRef]

36. Matthews, D.R.; Hosker, J.; Rudenski, A.; Naylor, B.; Treacher, D.; Turner, R. Homeostasis model assessment: Insulin resistance and $\beta$-cell function from fasting plasma glucose and insulin concentrations in man. Diabetologia 1985, 28, 412-419. [CrossRef] [PubMed]

37. Hu, L.; Li, L.; Xu, D.; Xia, X.; Pi, R.; Xu, D.; Wang, W.; Du, H.; Song, E.; Song, Y. Protective effects of neohesperidin dihydrochalcone against carbon tetrachloride-induced oxidative damage in vivo and in vitro. Chem. Biol. Interact. 2014, 213, 51-59. [CrossRef]

38. Suarez, J.; Herrera, M.; Marhuenda, E. Hesperidin and neohesperidin dihydrochalcone on different experimental models of induced gastric ulcer. Phytother. Res. 1996, 10, 616-618. [CrossRef]

39. Xia, X.; Fu, J.; Song, X.; Shi, Q.; Su, C.; Song, E.; Song, Y. Neohesperidin dihydrochalcone down-regulates MyD88-dependent and -independent signaling by inhibiting endotoxin-induced trafficking of TLR4 to lipid rafts. Free Radic. Biol. Med. 2015, 89, 522-532. [CrossRef]

40. Lina, B.; der Meulen, H.D.-V.; Leegwater, D. Subchronic (13-week) oral toxicity of neohesperidin dihydrochalcone in rats. Food Chem. Toxicol. 1990, 28, 507-513. [CrossRef]

41. Henning, S.J. Plasma concentrations of total and free corticosterone during development in the rat. Am. J. Physiol. Metab. 1978, 235, E451-E456. [CrossRef]

42. American Diabetes Association. Diagnosis and classification of diabetes mellitus. Diabetes Care 2005, 28, S5-S10. 
43. Kim, E.; Shin, J.-H.; Seok, P.R.; Kim, M.-S.; Yoo, S.-H.; Kim, Y. Phyllodulcin, a natural functional sweetener, improves diabetic metabolic changes by regulating hepatic lipogenesis, inflammation, oxidative stress, fibrosis, and gluconeogenesis in $\mathrm{db} / \mathrm{db}$ mice. J. Funct. Foods 2018, 42, 1-11. [CrossRef]

44. Lim, S.-m.; Kim, E.; Shin, J.-H.; Seok, P.R.; Jung, S.; Yoo, S.-H.; Kim, Y. Xylobiose prevents high-fat diet induced mice obesity by suppressing mesenteric fat deposition and metabolic dysregulation. Molecules 2018, 23, 705. [CrossRef] [PubMed]

45. Pałasz, A.; Cież, D.; Trzewik, B.; Miszczak, K.; Tynor, G.; Bazan, B. In the search of Glycoside-Based molecules as antidiabetic agents. Top. Curr. Chem. 2019, 377, 19. [CrossRef]

46. Zang, Y.; Igarashi, K.; Li, Y. Anti-diabetic effects of luteolin and luteolin-7-O-glucoside on KK-A y mice. Biosci. Biotechnol. Biochem. 2016, 80, 1580-1586. [CrossRef]

47. Wood, I.S.; Trayhurn, P. Glucose transporters (GLUT and SGLT): Expanded families of sugar transport proteins. Br. J. Nutr. 2003, 89, 3-9. [CrossRef]

48. Kuo, G.-H.; Gaul, M.D.; Liang, Y.; Xu, J.Z.; Du, F.; Hornby, P.; Xu, G.; Qi, J.; Wallace, N.; Lee, S. Synthesis and biological evaluation of benzocyclobutane-C-glycosides as potent and orally active SGLT1/SGLT2 dual inhibitors. Bioorg. Med. Chem. Lett. 2018, 28, 1182-1187. [CrossRef]

49. Kuroda, S.; Kobashi, Y.; Oi, T.; Kawabe, K.; Shiozawa, F.; Okumura-Kitajima, L.; Sugisaki-Kitano, M.; Io, F.; Yamamoto, K.; Kakinuma, H. Discovery of potent, low-absorbable sodium-dependent glucose cotransporter 1 (SGLT1) inhibitor SGL5213 for type 2 diabetes treatment. Bioorg. Med. Chem. 2019, 27, 394-409. [CrossRef]

50. Miller, P.E.; Perez, V. Low-calorie sweeteners and body weight and composition: A meta-analysis of randomized con-trolled trials and prospective cohort studies. Am. J. Clin. Nutr. 2014, 100, 765-777. [CrossRef]

51. Schäffler, A.; Schölmerich, J.; Büchler, C. Mechanisms of Disease: Adipocytokines and visceral adipose tissue-emerging role in nonalcoholic fatty liver disease. Nat. Clin. Pract. Gastroenterol. Hepatol. 2005, 2, 273-280. [CrossRef]

52. Maersk, M.; Belza, A.; Stødkilde-Jørgensen, H.; Ringgaard, S.; Chabanova, E.; Thomsen, H.; Pedersen, S.B.; Astrup, A.; Richelsen, B. Sucrose-sweetened beverages increase fat storage in the liver, muscle, and visceral fat depot: A 6-mo randomized intervention study. Am. J. Clin. Nutr. 2011, 95, 283-289. [CrossRef] [PubMed]

53. Antonio-Villa, N.; Bello-Chavolla, O.Y.; Vargas-Vázquez, A.; Mehta, R.; Aguilar-Salinas, C.; Group, M.S.S. The combina-tion of insulin resistance and visceral adipose tissue estimation improves the performance of metabolic syndrome as a predictor of type 2 diabetes. Diabet. Med. 2020, 37, 1192-1201. [CrossRef] [PubMed]

54. Hwang, Y.-C.; Fujimoto, W.Y.; Hayashi, T.; Kahn, S.E.; Leonetti, D.L.; Boyko, E.J. Increased Visceral Adipose Tissue Is an Independent Predictor for Future Development of Atherogenic Dyslipidemia. J. Clin. Endocrinol. Metab. 2016, 101, 678-685. [CrossRef] [PubMed]

55. Sam, S.; Haffner, S.; Davidson, M.H.; D'Agostino, R.B.; Feinstein, S.; Kondos, G.; Perez, A.; Mazzone, T. Relationship of Abdominal Visceral and Subcutaneous Adipose Tissue With Lipoprotein Particle Number and Size in Type 2 Diabetes. Diabetes 2008, 57, 2022-2027. [CrossRef]

56. Adeva-Andany, M.M.; Pérez-Felpete, N.; Fernández-Fernández, C.; Donapetry-García, C.; Pazos-García, C. Liver glucose metabolism in humans. Biosci. Rep. 2016, 36, e00416. [CrossRef]

57. Huang, X.; Liu, G.; Guo, J.; Su, Z. The PI3K/AKT pathway in obesity and type 2 diabetes. Int. J. Biol. Sci. 2018, 14, 1483-1496. [CrossRef]

58. Abeyrathna, P.; Su, Y. The critical role of Akt in cardiovascular function. Vasc. Pharmacol. 2015, 74, 38-48. [CrossRef]

59. Crewe, C.; Zhu, Y.; Paschoal, V.A.; Joffin, N.; Ghaben, A.L.; Gordillo, R.; Oh, D.Y.; Liang, G.; Horton, J.D.; Scherer, P.E. SREBPregulated adipocyte lipogenesis is dependent on substrate availability and redox modulation of mTORC1. JCI Insight 2019, 5, 129397. [CrossRef]

60. Kimura, N.; Tokunaga, C.; Dalal, S.; Richardson, C.; Yoshino, K.; Hara, K.; Kemp, B.E.; Witters, L.A.; Mimura, O.; Yonezawa, K. A possible linkage between AMP-activated protein kinase (AMPK) and mammalian target of rapamycin (mTOR) signalling pathway. Genes Cells 2003, 8, 65-79. [CrossRef]

61. Lee, D.; Lee, J.; Hong, M.-G.; Lee, B.-H.; Kim, Y.-M.; Chang, P.-S.; Kim, Y.; Yoo, S.-H. Optimization of leucrose produc-tion by dextransucrase from Streptococcus mutans and its application as an adipogenesis regulator. J. Funct. Foods 2017, 39, 238-244. [CrossRef]

62. Liu, W.; Huang, S.; Li, Y.; Li, Y.; Li, D.; Wu, P.; Wang, Q.; Zheng, X.; Zhang, K. Glycyrrhizic acid from licorice down-regulates inflammatory responses via blocking MAPK and PI3K/Akt-dependent NF- $\mathrm{BB}$ signalling pathways in TPA-induced skin inflammation. Med. Chem. Comm. 2018, 9, 1502-1510. [CrossRef] [PubMed]

63. Park, J.; Kim, H.-L.; Jung, Y.; Ahn, K.S.; Kwak, H.J.; Um, J.-Y. Bitter Orange (Citrus aurantium Linné) Improves Obesity by Regulating Adipogenesis and Thermogenesis through AMPK Activation. Nutrients 2019, 11, 1988. [CrossRef] [PubMed]

64. Seale, P. Transcriptional Regulatory Circuits Controlling Brown Fat Development and Activation. Diabetes 2015, 64, 2369-2375. [CrossRef] [PubMed]

65. Adams, M.; Montague, C.; Prins, J.; Holder, J.C.; Smith, S.A.; Sanders, L.; Digby, J.E.; Sewter, C.P.; Lazar, M.A.; Chatterjee, V.K.; et al. Activators of peroxisome proliferator-activated receptor gamma have depot-specific effects on human preadipocyte differentiation. J. Clin. Investig. 1997, 100, 3149-3153. [CrossRef]

66. Sears, I.B.; MacGinnitie, M.A.; Kovacs, L.G.; Graves, R.A. Differentiation-dependent expression of the brown adipocyte uncoupling protein gene: Regulation by peroxisome proliferator-activated receptor gamma. Mol. Cell. Biol. 1996, 16, 3410-3419. [CrossRef] 
67. Liang, H.; Ward, W.F. PGC-1 $\alpha$ : A key regulator of energy metabolism. Adv. Physiol. Educ. 2006, 30, 145-151. [CrossRef]

68. Puigserver, P.; Wu, Z.; Park, C.W.; Graves, R.; Wright, M.; Spiegelman, B.M. A cold-inducible coactivator of nuclear receptors linked to adaptive thermogenesis. Cell 1998, 92, 829-839. [CrossRef]

69. Xu, L.; Nagata, N.; Chen, G.; Nagashimada, M.; Zhuge, F.; Ni, Y.; Sakai, Y.; Kaneko, S.; Ota, T. Empagliflozin reverses obesity and insulin resistance through fat browning and alternative macrophage activation in mice fed a high-fat diet. BMJ Open Diabetes Res. Care 2019, 7, e000783. [CrossRef]

70. Kang, N.H.; Mukherjee, S.; Yun, J.W. Trans-cinnamic acid stimulates white fat browning and activates brown adipocytes. Nutrients 2019, 11, 577. [CrossRef]

71. Jiang, H.; Horiuchi, Y.; Hironao, K.-y.; Kitakaze, T.; Yamashita, Y.; Ashida, H. Prevention effect of quercetin and its glycosides on obesity and hyperglycemia through activating AMPK $\alpha$ in high-fat diet-fed ICR mice. J. Clin. Biochem. Nutr. 2020, 67, 74-83. [CrossRef]

72. Viskupičová, J.; Ondrejovič, M.; Šturdík, E. Bioavailability and metabolism of flavonoids. J. Food Nutr. Res. 2008, 47, 151-162.

73. European Food Safety Authority. Flavouring Group Evaluation 32 (FGE. 32): Flavonoids (Flavanones and dihydrochalcones) from chemical groups 25 and 30. EFSA J. 2010, 8, 1065. [CrossRef]

74. Kwon, E.-Y.; Lee, J.; Kim, Y.J.; Do, A.; Choi, J.-Y.; Cho, S.-J.; Jung, U.J.; Lee, M.-K.; Park, Y.B.; Choi, M.-S. Seabuckthorn Leaves Extract and Flavonoid Glycosides Extract from Seabuckthorn Leaves Ameliorates Adiposity, Hepatic Steatosis, Insulin Resistance, and Inflammation in Diet-Induced Obesity. Nutrients 2017, 9, 569. [CrossRef] [PubMed]

75. Zhang, H.; Hassan, Y.I.; Liu, R.; Mats, L.; Yang, C.; Liu, C.; Tsao, R. Molecular Mechanisms Underlying the Absorption of Aglycone and Glycosidic Flavonoids in a Caco-2 BBe1 Cell Model. ACS Omega 2020, 5, 10782-10793. [CrossRef] [PubMed] 